\title{
OBSERVAÇÕES SOBRE A SANÇÃO (SANCTIO) DAS LEIS EM DIREITO ROMANO
}

\author{
Aracy Augusta Leme Klabin \\ Professora Doutora aposentada da Faculdade de Direito \\ da Universidade de São Paulo
}

\begin{abstract}
Resumo:
$\mathrm{O}$ texto refere-se às lex perfecta, lex minus quam perfecta $\mathrm{e}$ imperfecta, tratando da sanção cominada em cada uma delas. Estabelece uma relação entre a possibilidade de anular ou-não os atos praticados contra as disposições das leis, bem como analisa a pena cominada aos atos contra os preceitos legais tanto no Direito Romano quanto no Direito moderno.
\end{abstract}

\begin{abstract}
:
The text refers to lex perfecta, lex minus quam perfecta and imperfecta, treating about the sanction applied in each one of them. It establishes a relation between the possibility of null or not the acts practiced against the law dispositions, as well analyses the sanction applied to the acts against the legal precepts both on Roman Law and modern Law.
\end{abstract}

Unitermos: Leis perfectae, imperfectae, praescriptio, rogatio, sanctio.

Propomo-nos neste trabalho a examinar a questão das leis perfectae, minus quam perfectae e imperfectae.

Contudo, para maior compreensão, devemos lembrar que a lex romana constava de três partes, a saber: 1. praescriptio, 2. rogatio e 3. sanctio. ${ }^{1}$

A praescriptio constituía o preâmbulo da lei. Nela figuravam seus elementos de identificação: nome do magistrado proponente, dia e lugar da votação, menção do primeiro votante e da tribo ou centúria praerrogativa, isto é, que abria o sufrágio.

A rogatio era o elemento essencial contendo o texto da lei proposta pelo magistrado.

1. Sobre a etimologia da palavra sanção, veja-se Inst. $2,1,10$. 
A sanctio cominava penas contra a violação da lei. Essa sanção é freqüentemente imperfeita.

Encontramos num texto de época tardia (Ulp. Reg. I, 1-2) a classificação das leis em leges perfectae, minus quam perfectae e imperfectae.

Regras de Ulpiano, Intr.

$1 \quad$ Leges aut perfectae sunt aut imperfectae aut minus quam perfectae. Perfectae lex est...Imperfectae lex est, quae fiere aliquid vetat, nec tamen, si factum sit rescindit: qualis est lex Cincia, quae plus quam...donare prohibet, exceptis quibusdam cognatis et si plus donatum sit, non rescindit.

2 Minus quam perfecta lex est, quae vetat aliquid fiere, et si factum sit, non rescindit, sed poenam injungit ei qui contra legem fecit: qualis est lex Furia testamentaria, quae plus quam mille assium legatum mortisve causa prohibet capere praeter exceptas personas et adversus eum qui plus ceperit quadrupli poenam constituit.

3 Lex aut rogatur, id est fertur, aut abrogatur, id est prior lex tollitur, aut derogatur, id est pars primae legis tollitur, aut subrogatur id est adicitur aliquid primae legi, aut abrogatur, id est mutatur aliquid ex prima leg".

Tradução

1 - "As leis são perfeitas ou imperfeitas ou menos que perfeitas. É perfeita a lei...É imperfeita a lei que proibe se faça alguma coisa e entretanto se se fizer, não anula o ato: tal é a lei Cincia que proíbe doar a mais de...e se se doar mais, não anula.

2 - Menos que perfeita é a lei que proíbe se faça algo e se se fizer, não anula o ato, mas comina uma pena ao infrator: tal é a lei Furia testamentaria proibindo receber por legado ou mortis causa mais de mil asses, exceptuadas algumas pessoas, e àquele que tenha recebido mais, impõe a pena do quádruplo.

A respeito das metamorfoses da lei escreve o mesmo Ulpiano (1,3): A lei é rogada quando proposta; abrogada quando abole a lei anterior; derrogada quando suprime parte da lei anterior; subrogada quando acrescenta algo à primeira lei; obrogada quando altera algo da primeira lei".

As leges perfectae recusam qualquer efeito ao ato praticado em contravenção a seu preceito. O termo técnico empregado para indicar essa ineficácia 
é rescindere. Caberá, então, ao pretor tirar as consequiências do princípio legal que no exercício de sua jurisdictio quer usando de seu imperium.

Em síntese as leges perfectae determinam a nulidade dos atos praticados contra as suas disposições. Exemplo dessa espécie é a lex Falcidia, de donis et muneribus, Lei rogada ou plebiscito do ano 40 a.C., proposta pelo tribuno $\mathrm{P}$. Falcidio e regulando a liberdade de legar bem como determinando que a quarta parte do acervo hereditário pertencesse ao herdeiro. Caso o testador tivesse feito legados acima dos limites da lei, tais legados seriam reduzidos proporcionalmente, ou melhor, se o testador distribuísse mais de três quartos de seu patrimônio em legados, estes seriam nulos quanto à quantia excedente.

Esta lei, que na época imperial sofreu modificações, conclui a série de expedientes destinados a evitar que diante de herança excessivamente onerosas, $o$ herdeiro se encontrasse na alternativa de renunciar ou de assumir encargos excessivos.

O caráter cogente da norma não parece ter sido observado no Direito Romano-Justinianeu.

Leges minus quam perfectae - são as que não declaram nulo o ato praticado contra seu preceito, mas impõem uma pena ao transgressor, freqüentemente de caráter pecuniário.

Exemplo da espécie é a Lex Furia Testamentaria, anterior a 169 a.C. Encontramos seu conteúdo em G. 2, 225; 4, 23, 24; Ulp. 28, 7; Inst. 2, 22, pr.

Foi um plebiscito (lei votada pela plebe) proposto pelo tribuno $\mathrm{C}$. Furio, dispondo que ninguém pudesse receber por legado valor superior a 1.000 asses e concedendo ao herdeiro uma ação executiva (manus injectio) contra o contraventor para exigir-lhe o quádruplo do excesso proibido; são excluídos da proibição os parentes consangüíneos do testador até o sexto e sétimo graus.

A sanção desta lei visa indiretamente evitar a transgressão, que uma vez cometida, acarreta pena a cargo do transgressor, sem contudo anular o ato.

O legislador considerou, socialmente, mais útil aceitar a validade do ato contrário à lei.

Juntamente com a Lex Furia devemos mencionar a Lex Voconia, plebiscito proposto pelo tribuno Q. Voconio Saxa, anterior à Lex Furia, e, que proibia deixar ao herdeiro, valor menor que o legatário mais favorecido. Impedia, ainda os cidadãos da primeira categoria do censo (com capacidade econômica superior a 100 mil asses) de instituir herdeiras as mulheres. 
Como outras leis (Voconia, Falcidia), a Lex Furia é uma inovação no sistema e na história do direito sucessório romano, com a intenção de impedir que o herdeiro sobre o qual recaísse todo o encargo da herança, ficasse reduzido à obrigação de somente distribuir os legados.

Até o aparecimento da Lex Furia não havia qualquer limitação legal à quantidade e ao número dos legados, ignorando-se qualquer exigência de relação proporcional entre os quinhões dos herdeiros e os dos legatários.

A Lex Furia revela o primeiro sinal de transformação nesta matéria, graças ao progresso da consciência social.

Em resumo, ela vetou os legados superiores a 1.000 asses, salvo quando fossem a favor do cônjuge sobrevivente, ou de outro parente até o $6^{\circ}$ ou $7^{\circ}$ graus.

É de se notar que essa lex, mesmo tendo representado a primeira expressão duma intervenção normativa na matéria, constituiu, todavia, remédio parcial porque deixou ao testador liberdade absoluta quanto à determinação do número de legados e porque não resolveu o problema teórico e prático de uma proporcionalidade entre o patrimônio e os legados. Assim, mesmo depois dela, subsistiu a situação iníqua do herdeiro.

No Direito moderno podemos encontrar exemplos de leis minus quam perfectae em nosso Código Civil, como no art. 183, ns. XIII a XVI, pois o casamento contraído com infração dele, não é nulo nem anulável, mas acarreta as penas dos arts. 225 e 226.

São em geral do mesmo tipo todas as disposições prevendo e punindo fatos materiais, pois factum infectum fieri non potest (D. 49,15,12,2); tome-se por exemplo o art. 395 do Código Civil.

Grande parte do Direito Penal compõe-se de leis menos que perfeitas, pois as conseqüências materiais do delito não podem ser eliminadas pela ordem jurídica. O mesmo de certo modo sucede no Direito das Obrigações em matéria de inadimplemento (arts. 1.056 e 1.518 do Código Civil). A responsabilidade por perdas e danos não-coincide com o adimplemento espontâneo; o fato do inadimplemento permanece.

Leges imperfectae são as leis que não cominam sanção alguma, isto é, nem declaram nulo o ato contrário a elas, nem impõem pena.

Exemplo típico de lei imperfeita é a Lex Cincia de Donis et Muneribus, plebiscito votado no ano 204 a.C. por proposta do tribuno M. Cincio 
Alimento, limitando de modo geral a liberdade das doações e impedindo as liberalidades prejudiciais aos patrimônios dos parentes próximos (heredes sui).

Essa lei continha duas disposições:

a) impedia os advogados de aceitarem dádivas pelos seus serviços; ${ }^{2}$

b) limitava a faculdade de doar, estabelecendo uma quantia (modus), que não conhecemos, acima da qual a doação não era permitida.

São muito obscuras a origem e a função da Lei Cincia, que os intérpretes costumam relacionar com o direito sagrado (fas).

$\mathrm{O}$ pretor negava a ação (denegatio actionis) a quem em juízo quisesse fundar-se em um ato jurídico contrário à lei ou dava um meio de defesa (exceptio) a quem tivesse sido chamado a juízo para cumprir um ato proibido pela lex imperfectae.

Assim, recorrendo à exceptio legis Cinciae contra o donatário, o doador ou o herdeiro conseguiam indiretamente paralisar os efeitos do ato; pagavam só até o limite permitido na lei.

2. (Nos últimos tempos da República as exigências dos advogados tomaram-se ilimitadas e a defesa tornou-se objeto de verdadeiro tráfico. Augusto tentou remediar a situação, revigorando a Lei Cincia e decretando, por meio de senatusconsulto, que o advogado contra o qual se provasse ter recebido qualquer retribuição do cliente fosse condenado a restituir o quádruplo.

A medida era detestável, pois já fora erro não compreender que a instituição do patronato só existia de nome e que a assistência judiciária se tornara profissão, merecendo remuneração condigna.

$\mathrm{Na}$ República, pelo menos, as instituições permitiam ao oratur encontrar nos cargos conferidos pelo sufrágio de seus concidadãos a retribuição dos serviços prestados.

Mas, dois séculos mais tarde, quando a autoridade soberana achava-se concentrada nas mãos do príncipe, os advogados vendo-se sem qualquer perspectiva de remuneração recorriam à delação para viver. Houve uma reforma tentada sem discemimento, que se tornou nova causa de desmoralização.

Contida, porém um instante, a avidez dos advogados tornou-se ainda mais audaciosa. Sob Cláudio (41-54 d.C.) um cavaleiro de nome Samio tinha pago 400 mil sestércios ao advogado Suilio, encarregado de sua defesa. Corrompido por soma ainda maior Suilio tergiversou, conluiando-se com o acusador de seu cliente que, desesperado, suicidou-se. (Tácio, Annales, XI, 1 a 8). culpado.

Revoltado contra essa prevaricação odiosa, o Senado exigiu a aplicação da Lei Cincia contra o

Na presença do imperador Suilio sustentou que essa lei tinha caído em desuso, não se the podendo aplicá-la sem certa retroatividade. Combateu, depois, as disposições da lei, procurando demonstrar que toda profissão deve satisfazer as necessidades de quem a exerça; o advogado deve viver do próprio talento como soldado da guerra e o camponês da terra.

O fato de homens já ricos atuarem desinteressadamente no tribunal não deve fazer esquecer outros, menos favorecidos pela fortuna e que obtiveram elevados honorários por suas defesas.

Privar, finalmente, o talento e o trabalho da justa remuneração devida seria desencorajá-los e aniquilá-los.

Tocado por tais considerações Cláudio pôs de lado a Lei Cincia, limitando-se a decidir que no futuro, sob pena de concussão, os advogados nada pudessem receber acima de 10 mil sestércios.). Apud Grellet-Dumazeau, Le Barreau Romain, 1 v., Paris, 1858, pp. 122-3. 
A exceptio legis Cinciae não-estendia sua eficácia a favor dos herdeiros do doador, quando este perseverasse em sua intenção até a morte. Tal exclusão da exceptio exprime-se na frase morte Cincia removetur.

Verificamos, então, que havia uma disposição especial proibindo os advogados de aceitarem doações de seus clientes em pagamento de serviços profissionais; a lei proibia sobretudo doações superiores a determinado limite, abrindo exceção em favor de parentes próximos e de certas pessoas privilegiadas (personae exceptae).

Permitia-se ao herdeiro exercer a manus iniectio contra o legatário titular dum legado superior àquela soma, bem como exigir como pena um múltiplo da importância excedente.

A Lei Cincia caiu em desuso na época pós-clássica.

No tempo de Justiniano as doações foram submetidas a novo regime, consistindo na feitura de um instrumento escrito e no registro público (insinuatio apud acta). O Direito Justinianeu declara nula a doação superior a 500 soldos.

A Lex Cincia de Donationibus foi revogada por Constantino (C. 8, 53, 25).

Depois da constituição de Teodosio II e Valentiniano III (C. 1, 14, 5, 439 d.C.) determinando em geral a nulidade dos atos praticados contra leis proibitivas, não há mais leges imperfectae, no tocante à validade daqueles.

No Direito Romano a categoria se justifica fundada na pluralidade dos ordenamentos jurídicos (sobretudo do jus civile e do jus honorarium).

No Direito moderno, as leges imperfectae se apresentam exatamente no Direito Internacional Público, cujas normas, embora segundo grocio se refiram a um direito das gentes já-existente, carecem afinal de sanção.

Parece surpreendente a existência de leis sem sanção.

Elas foram, entretanto, em Roma as mais numerosas, revelando certa timidez do legislador que ao formular um princípio não se julgava autorizado a sancioná-lo. Tal reserva, da qual há outros sinais, confirma a função modesta atribuída à lei durante o período republicano (510 - 27 a.C.).

Só no Baixo-Império será declarado nulo todo o ato contrário à lei (C. 1, 14, 5 ano 439) desaparecendo, então, completamente a classificação antiga das três categorias de leges. Quanto a este assunto no Direito moderno, podemos nos reportar aos seguintes artigos do nosso Código Civil: art. 1.287 (depositário infiel); arts. 1.780 e 1.781 (bens sonegados). Lembre-se, ainda, a Lei de Alimentos (n. 
5.478, de 25.07.1968, arts. 18 e 19) citada na tese do Professor Álvaro Villaça de Azevedo, Prisão Civil por Dívida (São Paulo, 1992), pp. 141 e seguintes. E, mais, o art. 733 do Código de Processo Civil atual.

São Paulo, janeiro de 1996.

\section{BIBLIOGRAFIA}

Novíssimo Digesto Italiano, v. IX.

LISSNER, Ivar. Assim viviam os nossos antepassados. Belo Horizonte : Itatiaia Ltda.

CORREA, Alexandre e SCIASCIA, Gaetano. Manual de Direito Romano. São Paulo : Saraiva, 1949. vs. 1 e 2.

SHERWIM-WHTE, A. N. The Roman Citizenship. Oxford : Clarendon Press, 1939.

GUTIERREZ-ALVIZ, F. Dicionario de Derecho Romano. Madrid : Reus S.A., 1982.

PORCHAT, Reynaldo. Curso Elementar de Direito Romano. São Paulo : Duprat \& Cia., 1907. v. 1.

The Oxford history of the Roman World. Edited by John Boardman etc. Oxford University Press, 1986.

SMITH, Munroe. The Development of European Law. Columbia University Press, 1928.

RÁO, Vicente. O Direito e a Vida dos Direitos. v. 1.

BERGER, Adolf. Encyclopedic Dictionary of Roman Law. Philadelphia, 1953. v. 1.

GAUDEMET J. Institutions de l'Antiquité. Paris, 1967. v. 1 p. 393.

GRELLET-DUMAZEAU. Le Barreau Romain. Paris, 1858. v. 1 pp. 122-3. 